\title{
Debate
}

\section{Why the fair innings argument is not persuasive Michael M Rivlin}

Address: School of Philosophy, University of Leeds, Leeds, England. E-mail: Michael M Rivlin - rivlin@globalnet.co.uk

Published: 21 December 2000

BMC Medical Ethics 2000, I:I

This article is available from: http://www.biomedcentral.com/I472-6939/I/I
Received: 10 December 2000

Accepted: 21 December 2000

\begin{abstract}
The fair innings argument (FIA) is frequently put forward as a justification for denying elderly patients treatment when they are in competition with younger patients and resources are scarce. In this paper I will examine some arguments that are used to support the FIA. My conclusion will be that they do not stand up to scrutiny and therefore, the FIA should not be used to justify the denial of treatment to elderly patients, or to support rationing of health care by age.

There are six issues arising out of the FIA which are to be addressed. First, the implication that there is such a thing as a fair share of life. Second, whether it makes sense to talk of a fair share of resources in the context of health care and the FIA. Third, that 'fairness' is usually only mentioned with regard to the length of a person's life, and not to any other aspect of it. Fourth, if it is sensible to discuss the merits of the FIA without taking account of the 'all other things being equal' argument. Fifth, the difference between what is unfair and what is unfortunate. Finally, that it is tragic if a young person dies, but only unfortunate if an elderly person does.
\end{abstract}

\section{Discussion}

At first sight the FIA is attractive. Appeals to fairness and intuition appear to support the idea that finite resources should be directed at the young, who have not had a chance to live their lives, in preference to elderly people, who have already lived a major part of theirs. However, I will attempt to show why the arguments supporting the FIA do not stand up to scrutiny.

\section{A description of the FIA}

John Harris describes the FIA as follows: 'The fair innings argument takes the view that there is some span of years that we consider a reasonable life [for a person to have had], a fair innings. Let's say that a fair share of life is the traditional three score and ten, seventy years. Anyone who does not reach 70 suffers, on this view, the injustice of being cut off in their prime. They have missed out on a reasonable share of life: they have been shortchanged. Those, however, who do make 70 suffer no such injustice, they have not lost out but rather must consider any additional years a sort of bonus beyond that which could reasonably be hoped for. The fair innings argument requires that everyone be given an equal chance to have a fair innings, to reach the appropriate threshold but, having reached it, they have received their entitlement' [1]. Harris, later in the same chapter writes, '... I am inclined to believe that where two individuals both equally wish to go on living for as long as possible our duty to respect this wish is paramount. ... Each person's desire to stay alive should be regarded as of the same importance and as deserving the same respect as that of anyone else, irrespective of the quality of their life or its expected duration. This would hold good in all cases in which we have to choose between lives, except one. And that is where one individual has had a fair innings and the other not. In this case, although there is nothing to chose between the two candidates from the points of view of their respective will to live and both would suffer the injustice of having their life cut short when it might continue, only one would suffer the further injustice of being deprived of a fair innings - a benefit the other has received ... The fair innings argument points to the fact 
that the injustice done to someone who has not had a fair innings when they lose out to someone who has is significantly greater than in the reverse circumstances. It is for this reason that in the hopefully rare circumstances where we have to choose between candidates who differ only in this respect we should choose to give as many as possible the chance of a fair innings' [1]. (I have quoted Harris in full here for two reasons. First it is a good and full description of the FIA. Second, so I cannot be accused of misrepresenting the FIA.)

There are, it seems to me, six issues that are either raised directly by, or arise out of, Harris's description of the FIA that need to be addressed. First, the implication that there is such a thing as a fair share of life. Second, whether it makes sense to talk of a fair share of resources in the context of the FIA. Third, that 'fairness' appears only to be mentioned with regard to the length of a person's life, and not to any other aspect of it. Fourth, whether we can sensibly discuss the merits of the FIA without taking account of the 'all other things being equal' argument. Fifth, the difference between what is unfair and what is unfortunate. Finally, the idea that it is tragic if a young person dies, but only unfortunate if an elderly person does. I will deal with each of these in turn.

\section{What is meant by a fair share of life?}

As noted, Harris refers to 'a fair share of life'. He writes, 'Let's say a fair share of life is 70' [1]. But what is meant by this? It may be helpful when discussing 'fair shares' to think in terms of a cake that is to be divided, as it forces us to ask three important questions. They are: 'what is being shared?', 'who is it being shared between?' and, 'are people entitled to a share of it?' In taking this simple example of a cake, we can by contrast see why talking of a fair share of life (or a fair share of $a$ life) does not in fact make sense. Whilst we may well know the size of a cake to be shared, we do not know the length of a life (until it is over). Second, whereas a cake is divisible - a life is not. Third, having a share of something implies that (a) we can trade it (There are ways that we can almost trade our lives. For instance, if a person was to sell a vital organ to clear a debt. Although is at present illegal (in the UK) for a person to do so, there has been a call to allow the sale of kidneys [2]) (b) we can give our share of it away and (c) we can decline it. As regards the first point, we obviously cannot trade life. With regard to (b), it seems strange to think of years of life as something that can be given way. As a parallel example, we can give away our piece (or share) of a cake. However, we cannot give to another person say five years of our life. As for (c), all that we can do is refuse treatment in the hope that someone else may benefit from the resources we have refused, but of course there is no guarantee that they will be able to do so. It is unlikely in any case that we would be permitted to designate to whom the resource that we are refusing should be given. We are unable therefore to give them more shares of life. (Although we can stipulate that we would only allow an organ to be removed from our body in order to give it to one of our children, it is doubtful if we could refuse a bed in hospital or a place on a dialysis machine, on the understanding that it was given instead to a person of our choice.) We certainly cannot give them a share of our life. All the above points suggest that it does not really make sense to talk of having a fair share of life.

Inherent in the FIA is the notion that it is unfair when a younger and an older patient are in competition for a resource, to prefer the latter, as he has already had more time alive than the younger patient. I accept that the analogy of the cake cannot take the question of time alive into consideration. However, that it is necessarily unfair to prefer the older patient in such a situation can be challenged and I will indeed do so when the 'all other things being equal argument' is looked at shortly.

\section{Does it make sense to talk of a fair share of resources in the context of a fair innings?}

Daniel Callahan believes that it makes sense to talk of elderly people having had their fair share of resources. He writes, '... beyond a certain point that [elderly people] will have already had their fair share of resources' [3].

But it will be recalled that there were three criteria that needed to be established before we could meaningfully answer the question when we asked 'what is meant by a fair share of life?' Similarly, before deciding if it makes sense to talk of a fair share of resources, we need to know the amount or size of what is being shared, the numbers of those among whom it is being shared among, and whether the claimants have any entitlement to it. It might, at first sight, be thought that in the case of the NHS we do know the amount of what is to be shared. It is the sum that government allocates to it. But this amount is subject to continuous change, determined by the government's spending priorities, subject to fluctuation at the will of the legislature and often influenced by both public opinion and the media.

Furthermore, if one attempts to establish the nature of health care resources, it soon becomes clear that it is virtually impossible to quantify them. For instance, should nurses' overtime be counted as a resource, or only their contracted hours? Should a hospital building be regarded as a resource if it is mortgaged? Should the time a doctor spends training to be a consultant be considered as a resource for those people who are currently patients (but who might die before he completes his training) or only for future patients? 
Even if we did know the extent of the resources available, we do not know the numbers of those whom between it is to be shared. Although we may be aware of the country's total population, there may in fact be 'others' to be legitimately considered as well. For example, when thinking of fair shares, should we not save some of the available resources for people who do not yet exist? There are many instances where actions are taken intended to benefit those not yet born, and not just - perhaps not even primarily - those who are currently alive. It is reasonable to suppose that much of current medical research will be of more value to future generations than to those who are living now. It seems that we are therefore prepared to allocate some of our resources (that could be spent on people living today) to the well being of those in the future. However, even if we restrict our attention to current users of health care, we do not know how many of them will require treating, nor do we know how much treatment they will need. It can now be seen where all this is leading. If we cannot decide what a fair share is, how is it possible to decide on our fair share? Therefore, talk of elderly people having more of their fair share or younger people less, makes no sense when discussing the FIA.

\section{Fairness}

I have tried to establish that is it is not sensible to talk of fair shares in the context of the FIA (or indeed in the allocation of scarce health care resources). But that does not mean that I cannot show that age-based rationing (ABR) (when ABR is mentioned or alluded to in this paper it will be on the basis that elderly people are denied access to treatment that could benefit them solely, principally, or partly because of their chronological age, and to which younger patients are not denied access) of health care is unfair, or that we cannot agree on what unfairness (in many situations) is. John Stuart Mill writes, '... for justice, like many other moral attributes, is best defined by its opposite' [4]. Although the notion of fairness is vague it is possible to distinguish between various kinds of unfairness. Unfairness for instance is not confined to distributive justice. As an example, a kind of unfairness that makes sense to us is cheating - which need not be taking more than one's share: it may be a matter of departing from agreed rules. If you and I have decided to play a game in which it is agreed that we can field teams of 11 players, and I sneak an extra player on to the pitch with the aim of gaining an advantage, I would be acting unfairly. The issue of 'fair shares' simply does not arise. If a policeman plants drugs on an innocent person with a view to gaining a conviction he is acting unfairly. Again, fair shares is not an issue here.

A major problem with the FIA is that discussion of fairness is limited to length of life. Professor Alan Maynard writes, "The efficient use of scarce healthcare resources might not be the only objective of society. Society might be prepared to forego efficient health gains in order to behave 'fairly' ... One possible definition of 'fairness' in health care is that decision makers will use the NHS to reduce inequalities in people's lifetime experience of health. Such an approach reflects the idea of a 'fair innings' and could support the transfer of health gains from elderly people - who have had their 'three score years and ten (or, hopefully more) - to younger people. Thus the NHS might deny efficient treatments - such as hip replacements or coronary artery bypass grafting - to those who have had a fair innings in order to redistribute resources and inefficiently treat young, chronically ill patients' [5]. (Why would treating chronically ill patients be unfair?)

I accept that fairness is a difficult concept to define, but why has Maynard chosen to use only 'a fair innings' - age as expression of what is fair in the context of the allocation of scarce health care resources? For instance, it might be considered unfair that a young drunken driver who has injured himself through reckless behaviour is preferred for treatment over an elderly person who is not to blame for his illness. A consultant in an accident and emergency department remarked to a friend that he was fed up with patients having to wait hours for treatment as a result of the department being full of young people who had been badly hurt due to their heavy drinking. Or, why would it be considered fair to prefer the younger person in a situation where there are two claimants for treatment, one aged 25 and the other aged 75, the former already having received a large amount of health care resources as a result of his anti-social behaviour and the latter, due to living a responsible life style having not had to call on the NHS, but at an advanced age needing the hip replacement to which Maynard refers? In these examples my complaint is not that older people are not receiving their fair share, but that the younger people are being preferred unfairly, i.e. just because they are young.

Before continuing, I want to look at the three ways ABR can be implemented. They are:

1. By macro rationing. This is where there is a national policy which states a particular drug or treatment should not be given to a person just because they are old. I have not come across such a policy. In fact all the political parties are at pains to state that ABR should not be countenanced.

2. By meso rationing. This occurs where a department has a policy (which can be implicit or explicit -written or unwritten) that states those over a particular age should not be treated. There are many instances of this. For example, several heart transplant units do not put anyone over 60 on their waiting list and some stroke rehabilitation units will not admit anyone over the age of 65 . 
3. By micro rationing. This is rationing at the bed side and occurs when a GP for example refuses to refer an elderly patient to a consultant on the basis that the doctor feels the patient is too old, irrespective of the benefit the patient might gain from a consultation and the fact the patient would opt for it given the chance.

Why is it always unfair to deny elderly patients treatment on a meso basis and sometimes on a micro one? With regard to meso rationing, suppose that, because of the expense of administering justice on an individual basis, it was decided that all 18-year olds accused of violent crimes would be jailed without a trial on the basis that statistics showed it was that age group that was were responsible for the majority of such crimes, would we not feel outraged because of the unfairness involved? Why then should we not feel that it is unfair that all elderly people be disadvantaged just because some within that group use up a large amount of resources, or might have less years to live than others? If it is regarded as unfair to deny individual 18-year olds justice, should it also not be regarded as equally unfair to deny individual elderly people health care without them being individually assessed? Moreover deciding policies on the basis of a group means that some people would be denied treatment, even if, for relatively small expense, they could be given many extra years, or an enhanced quality of life.

Furthermore, if it was considered fair to give treatment to those with a greater life expectancy then does it not follow that it is also fair to treat women in preference to men and to treat those in the higher socio-economic classes in preference to those in the lower, as the former in both instances are known to live longer. None of these things makes any real sense.

With regard to micro rationing, it would be unfair to deny elderly patients health care if the doctor's decision was based on pejorative attitudes towards elderly people. For example, at a meeting of GPs which took place in January 2000 the chairman asked how many of them practised ageism, 30\% signified that they did. When questioned about why they did so, many of the GPs gave the FIA as a reason. Others said that they would prefer using their limited resources on younger patients.

Supporters of the FIA may reply that a patient's potential years might not be the only thing being considered when allocating treatment; that the potential life years of a claimant should be a consideration but not the only one. However, whether in fact age would be decisive depends how ABR is implemented. If it was implemented on a meso level, i.e. no patient over 65 was to be admitted to an intensive care bed or a coronary care unit, then age would here be decisive. And, as I have attempted to show, denying elderly people health care on this basis is actually unfair.

I accept it might appear that fairness dictates that a younger person should be treated before an older one. After all, the older person has already had more of something (life) than the younger person has. Rather than give even more to someone old we should instead treat the younger patient. Surely fairness is an issue here. Though such a view is perfectly understandable, it seems to me that fairness might only be an issue 'if all other thing were equal' and as I will explain next, it will be my submission that they cannot be.

\section{The 'all other things being equal' argument}

We can look at the 'all other things being equal' argument in two different ways. First, as a practical proposition for rationing health in which a patient's chronological age is used as a tie-breaker in deciding which of two individuals to treat. Or, secondly, as a thought experiment along the lines, 'In a hypothetical situation in which all other things than age were equal, would it then be permissible to use age as a tie breaker?' As ABR is a daily part of life in the NHS [6] and as the FIA and all other things being equal argument are often used to justify ABR (see below) it does seem reasonable to discuss the 'all other things being equal' argument in the context of it being a practical method of deciding which patient to treat.

Professor Richard Lilford, in replying to an article in which I attacked ABR [7] writes, '... what should our policy be if two people arrive in an emergency department with the same prognosis for recovery and the only distinguishing feature is that one is 30 and one is 80 . To whom should we allocate the only remaining ventilator, intensive care bed, artificial lung machine etc. ... So what would Rivlin do with my two injured patients in the accident and emergency department: would he allocate the scare resources to the younger person, or simply go back to his department of philosophy and leave the doctor on the spot to decide?' [8]. The implication is that, in such cases as the one outlined here, it is reasonable to use age as the deciding factor in whom to treat.

But there is a major flaw in Lilford's reasoning. His argument assumes that all other things can be equal. (It does not seem unreasonable to assume that this is what Lilford meant as he suggested that age should be used as a tie-breaker ... 'if the only distinguishing feature was a substantial difference in their ages.') However, they cannot be and it is a misleading distraction to suggest that they can. It is in fact not possible for two patients to have an identical condition, bearing in mind the differences between both of a medical and, just as importantly, a social kind, that might have a significant effect on the health and prognosis of individuals. (One cannot get 
round this by saying that it is enough that there be material differences, as we would then have to decide what constitutes 'material' in this context.) For instance, factors that vary greatly between patients include how well they can communicate with their doctors, their ability to follow the physician's instructions, how they respond to treatment, and their lifestyle. All or any of these may have an enormous effect on how an illness progresses and might contribute positively or adversely to their well-being. The social circumstances of two claimants also cannot possibly be the same and this may effect the treatment they receive. In view of the above, even if it was accepted that age should be used as a tie-break, there are not likely to be any ties.

\section{The difference between what is unfair and what is unfortu- nate}

It is important to distinguish between what is unfair and what is merely unfortunate, in the context of the FIA. Simmons, discussing 'fairness' in the Encyclopaedia of Ethics, writes, "The standard context in which problems of fairness arise is one involving social co-operation aimed at a mutually beneficial end, though considerations of fairness clearly arise as well in nonvoluntary arrangements and ... in contexts which are only remotely 'distributive' - as when [a] ... debilitating handicap is called unfair' [9].

There is a crucial misunderstanding in the last part of what Simmons reports here, which requires addressing. To suggest that a person with a debilitating congenital handicap has been subject to 'an unfairness' presupposes that everyone has a right to be born as perfect as everyone else. Simmons seems not to be differentiating between 'unfortunate' and 'unfair'. Whereas it might be said that it was unfortunate that a person did not win the National Lottery, surely it could never plausibly be suggested that it was unfair that he did not do so. Unfairness only arises if some human agency brings it about.

Early in this paper we noted that, in his definition of the FIA, John Harris writes of those who have missed out on a reasonable share of life as being 'short-changed', and that those 'who do make 70 suffer no injustice'. The inference here is also that being short-changed is unfair (they are not getting the change they are due) as is not reaching the age of 70 . (We should note here that Harris writes, 'the injustice done to someone who has not had a fair innings is significantly greater than in the reverse circumstances'. Presumably then he accepts that there is some injustice being done to the older person if he is denied treatment in order that someone younger may benefit.) It is worth noting that Harris refers to an 'injustice' when a person does not achieve a fair innings [1]. But he does not mention that it may just be 'unfortunate' that they do not reach 70, and not unjust. Of course, Harris might mean that the injustice lies in giving an older patient treatment in preference to a younger one. However, before it can be said that it is unfair that a person has not achieved a 'fair innings', it must be stated why it is unfair, and explained why it is simply not unfortunate. As Nicholas Rescher writes in his book Luck, '... like it or not, luck is an ineliminable part of the human condition ... [it is] for better or worse - a major factor in our lives' [10]. He later writes, 'With matters of luck the whole idea of fair/unfair simply does not apply, because fairness is excluded in the nature of the case' [11]. If the FIA is to be credible, it is important that it takes into account the distinction between what is unfair and what is unfortunate. However, as I have attempted to show, the FIA does not do this, and therefore the argument fails because it trades on the assumption that what is unfortunate is automatically unfair.

Some of those who do not reach old age might just be unlucky, and it is not (as Harris for instance claims) that it is unjust that they do not do so. But it may be asked, 'is there not a duty of those who can prevent 'bad luck' to do so'? My feeling is that if we have any duties at all in these matters our primary duty would be to prevent an injustice.

Harry Lesser writes in discussing the FIA, 'It could also be argued that some of the elderly who have had hard lives when young may have had much less of the enjoyable part of their lives than some younger people, and could claim in a real sense that they have not yet 'had their fair innings' [12].

\section{Tragic v. unfortunate}

The idea that it is tragic if a person dies young but only unfortunate when an older person dies may have intuitive appeal, but falls down when we consider our feelings towards, say, the death of a 25 year old heroin pusher and that of a 70-year old grandparent who is doted on by his children and grand children. Would we here be so ready to think of the young criminal's death as more tragic than that of the grandparent? It is not certain that we would; and if this is the case, then the 'tragic v. unfortunate' argument collapses into a social debate about which of two people deserves treatment, based on our appraisal of their lifestyles.

Another example illustrates the point. Consider the situation in which two people have been killed in an automobile accident, one a joyrider who had stolen a car, the other a mother, teacher or nurse whom the joyrider had crashed into. Would we find it more tragic that the driver of the car was killed? It seems plausible that we would not, even if we were told that he was the younger of the victims. The point I am making is that it is not true that we necessarily see the death of a young person as being 
more tragic than that of an older one. What I am trying to show here is that our views of what is tragic may change as further facts are known. Similarly, with regard to fairness. Our views of whether something is fair may change when further things become apparent.

I accept that many people would regard the death of a young person as being a greater tragedy than that of someone who dies when they are old. This view is bound up with the notion that a young person's death is a premature one. But surely, if an elderly person is denied treatment and he dies as a result, then that person's death is also premature, and should therefore also be regarded as being tragic. As Wicclair writes '... even if it is the case generally that unprevantable death from natural causes of people over seventy-five or eighty is properly understood as 'an acceptable event', it does not follow that it is generally acceptable to withhold life-extending medical care from people over seventy-five or eighty. It also does not follow that it is generally improper for people over seventy-five or eighty to desire life-extending care that would enable them to continue to pursue their interests' [13]. Of course the death of a young person might be regarded as being more tragic, but it seems odd to suggest that whether a person receives medical treatment should depend on how we compare the tragicness of the situation of claimants for a resource, (and even if it was, how could 'tragicness' could be qualified?).

\section{Conclusion}

Attempting to be fair is supposedly what the FIA is all about. Having examined some of the reasons (given or implied) that are used to justify using the FIA it seems to me that they are not persuasive. Being fair does not, contrary to what supporters of the FIA claim, mean that we should discriminate against elderly patients on the grounds of fairness. This being the case, it seems to me that there are no grounds for using age as a basis for rationing health care on the basis of the FIA. Proponents of ABR must try and find better and different arguments for their cause.

\section{References}

I. Harris J: The Value of Life, an Introduction to Medical Ethics. London: Routledge \& Keegan Paul, 1970,

2. Radcliffe-Richards J: The case for kidney sales. The Lancet 1998, 3 I 2:1950-1952

3. Callahan D: Setting Limits. Medical Goals in an Aging Society. New York, Simon and Schuster 1987,

4. Mill JS: Utilitarianism. On Liberty, Essays on Bentham. Cleveland: Meridian Books 1968,

5. Maynard A: Rationing health care. What use citizen's juries and priority committees if principles of rationing remain implicit and confused? BM] 1996, 3/3:1499-

6. Sutton GC: Will you still need me, will you still screen me, when I'm past 64? BM] 1977, 3 15:1032-1033

7. Rivlin MM: Protecting elderly people: flaws in ageists arguments. BMJ 1995, 310:1 179-1182

8. Lilford RJ: Doctors need pragmatic strategies. BMJ I995, 3। I:752-
9. Simmons E: Fairness. In Encyclopaedia of Ethics. Edited by Becker $L$ Becker D. New York: Garland Publishing, 1993,

10. Rescher N: Luck. New York: Farrar Strauss Giroux, 1970,

II. Rescher N: The Allocation of exotic lifesaving therapy. Ethics 1969, 79:173-186

12. Lesser H: Ageing and Autonomy. Aldershot, Ashgate, 1998,

13. Wicclair MR: Ethics and the Elderly. New York: Oxford University Press, 1993,

\section{Pre-publication history}

The pre-publication history for this papercan be accessed here:

\section{http://www.biomedcentral.com/content/ backmatter/1472-6939-1-1-b1.pdf}

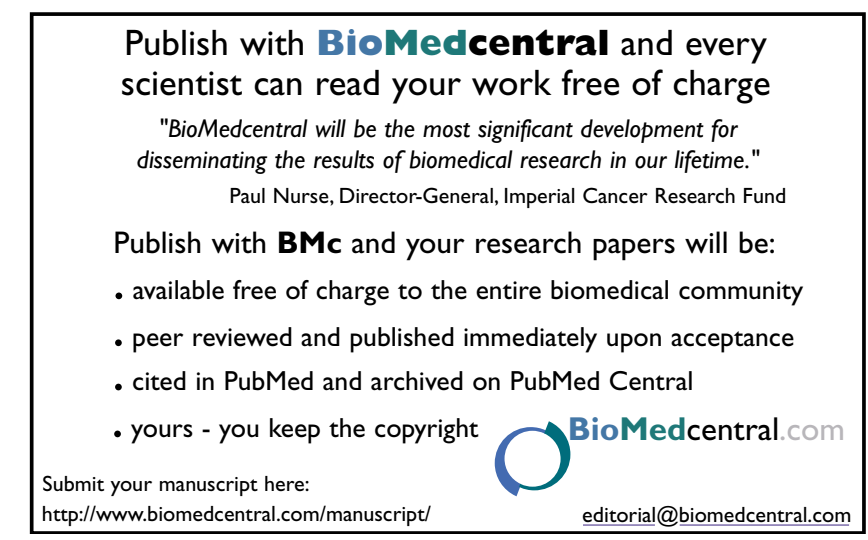

